\title{
Air quality and climate change in small states of the Commonwealth: Jamaica and Namibia
}

\author{
N. Kgabi ${ }^{1}$, L. Nampadhi ${ }^{1}$, J. Williams ${ }^{2}$, O. Hamilton ${ }^{2}$, \\ J. Antoine ${ }^{2}$, J. Preston ${ }^{2} \&$ C. Grant ${ }^{2}$ \\ ${ }^{1}$ Polytechnic of Namibia, Namibia \\ ${ }^{2}$ International Centre for Environmental and Nuclear Sciences, Jamaica
}

\begin{abstract}
Most air quality studies conducted in small states of the Commonwealth including Jamaica and Namibia do not address the interaction between the two main pollutants (particulate matter and tropospheric ozone), as well as their relationship with climate change. Total suspended particulates (TSP) and tropospheric ozone were measured in Windhoek, Namibia; while only TSP was measured in Kingston, Jamaica. The observed concentrations were used together with secondary data and/or calculations of atmospheric conditions like mixing height, temperature, wind speed, relative humidity, solar radiation, and ventilation rates to determine the PM-Ozone interactions and possible relationship with climate change. The TSP concentrations were high in Kingston than in Windhoek. The ozone concentrations in Windhoek were relatively low (10 to $35 \mathrm{ppb})$. The atmospheric pollutant interactions were observed as in order of relative abundance as Kingston $>$ Windhoek for TSP, relative humidity, mixing height, and ventilation rate; and Windhoek $>$ Kingston for solar radiation. The morphology of particulates also showed the effect of daily activities of the domestic, traffic and industrial sectors to air quality and ultimately climate, and which need to change for realization of reduced pollution and climate effect. The particulate-ozone interactions during ozone and smog formation can, depending on the source and type of aerosols, give an indication of the contribution to climate variability.

Keywords: particulate matter, tropospheric ozone, climate change, meteorological parameters, atmospheric conditions, Jamaica, Namibia.
\end{abstract}




\section{Introduction}

The close connection between climate and air quality is mostly reported in the form of impacts of climate change on air pollution levels; and to a lesser extent in the impacts of air pollution on climate change. While most air quality studies worldwide agree that aerosols, which are spread globally but have a strong regional imbalance, change global climate through their direct and indirect effects on radiative forcing [1]; and that the effect of tropospheric ozone on climate is understandable, relatively few confirm that the effect of climate change on particulates is more complicated and uncertain than for ozone.

Changes in climate affect air quality by perturbing ventilation rates (wind speed, mixing depth, convection, frontal passages), precipitation scavenging, dry deposition, chemical production and loss rates, natural emissions, and background concentrations [2]. Thus the complex interactions between emissions, atmospheric changes, and chemistry must be considered for a more comprehensive assessment of the influence of climate change on regional air quality [3].

Karl and Trenberth [4] confirmed that there remain many scientific, technical, and institutional impediments to precisely planning for, adapting to, and mitigating the effects of climate change. Despite the high vulnerability to climate change, which necessitates quantification of air quality as argued by researchers including Mkoma [5]; there are very few scientific air quality studies in Namibia and Jamaica, and the laws and regulations for monitoring of air quality are not based on national/local source apportionment and toxicological studies. The existing data are sourced from project-specific air quality studies, usually undertaken as specialist studies in Environmental Impact Assessments [6]. Climate change studies on the other hand, do not clarify the link between air quality and climate change beyond the greenhouse gases. This makes it difficult for policy makers to create awareness and regulate human activities that generate other air pollutants (including particulate matter and tropospheric ozone), which could help increase adaptive capacity of the vulnerable communities.

The aim of this study is thus, to determine the PM-Ozone interactions and possible relationship with climate change using calculations of air qualitymeteorological (PM, ozone, mixing height, ventilation rate, temperature, relative humidity, solar radiation) correlations. Mixing layer height (h) is an important parameter for understanding the transport process in the troposphere, air pollution, weather and climate change [7].

Jamaica and Namibia were selected to represent two contrasting (arid and tropical) environments. The two countries (together with Botswana, Lesotho and Papua New Guinea) are classified by the Commonwealth as "small states" because they share similar characteristics including susceptibility to natural disasters and environmental change with small states [8].

The findings of this study are significant to local, regional and global communities because conventional air pollutants such as ozone and particle pollution contribute to climate change; and because ozone and particle pollution stay in the atmosphere for only a few days or weeks, reducing these emissions can help reduce climate impacts in the near-term [9]. 


\section{Materials and methods}

Study sites: This study was conducted in two cities, Kingston in Jamaica and Windhoek in Namibia, each having four study sites as shown in Table 1.

Table 1: Location of study sites.

\begin{tabular}{|c|c|c|}
\hline SITE & COORDINATES & ELEVATION (ft) \\
\hline \multicolumn{3}{|c|}{ Windhoek, Namibia } \\
\hline ENG & 22 33’53.56” S, 17 04’27.99” E & 5469 \\
\hline H\&S & 22 33’57.53” S, 17 04’25.63” E & 5451 \\
\hline LECT & 22 33'53.36” S, 17 04'39.84” E & 5502 \\
\hline OFF & 22 33'54.97” S, 17 04’36.97” E & 5515 \\
\hline \multicolumn{3}{|c|}{ Kingston, Jamaica } \\
\hline APPLIED & 1800 '14.4” N, 076 45'00.7” W & 590 \\
\hline INORG & $1800^{\prime} 15.5 ” \mathrm{~N}, 076$ 44'56.7” W & 599 \\
\hline ICENS & 18 00’24.7” N, $07644^{\prime} 58.2$ " W & 614 \\
\hline LMCC & $1800^{\prime} 05.2^{\prime \prime} \mathrm{N}, 076$ 45’42.2” W & 1007 \\
\hline
\end{tabular}

TSP measurements: Single bucket fallout monitors were deployed following the American Society for Testing and Materials standard method for collection and analysis of dust fallout (ASTM D1739). Dust fallout bucket is a world known and accepted method used to monitor fall-out dust from various sources [10]. The procedure was carried out for eight (8) consecutive weeks. Once returned to the laboratory, the contents of the bucket were filtered out (onto $125 \mathrm{~mm}$ ashless filters) using a Buchner funnel connected to the diaphragm vacuuming pump, and the residue was dried before weighing. Gravimetric analysis of the dust samples was performed with a Mettler AT261 Delta Range with accuracy of 1/100 mg.

Morphological analysis: Morphological analysis of the TSP from the Namibian study site was performed using Olympus BX40 light microscope with Tilting Binocular Head; Olympus 4X, 10X, 40X, and 100X objective; and fitted with Olympus Abbe Condenser was used to determine the particle size and to acquire photomicrographs of the most abundant particles in the dust samples [6].

Ozone measurements: The Bieler+Lang GMC 8002 system was used to determine the level of tropospheric ozone Namibian study site. The gas monitor sensor which determined the tropospheric ozone, O3 was attached to the GMC 8002 and the readings of the sensor were then displayed on the GMC 8002. The system, as shown in the picture above, was set up at $1.6 \mathrm{~m}$ from the ground and the sensors were $2.15 \mathrm{~m}$ from the ground. The system was approximately $33 \mathrm{~m}$ from the construction and $26 \mathrm{~m}$ from Wagner Street. The system was put at the height in order for the sensors to be mounted above the wall to capture the ozone readings in the surrounding and not necessarily in the laboratory. 
Meteorological data: The meteorological data for the Jamaican study sites were obtained from Department of Physics, University of the West Indies, while the Namibian data was sourced from Biota Africa Weather [11] and Weather Underground [12].

\section{Discussion of results}

The results for TSP measurements conducted at Kingston during the end Winter to beginning of Spring (14 January to 18 February 2015) and TSP and Tropospheric Ozone measurements conducted at Windhoek during Spring season (8 September to 31 October 2014 with a two weeks gap between) are discussed in this section. The TSP was measured for 4 weeks and ozone, eight weeks.

\subsection{Particulates/aerosols and meteorological parameters}

Figure 1 shows the concentrations measured in (a) Windhoek, Namibia and (b) Kingston, Jamaica; and Table 2, the associated meteorological parameters.

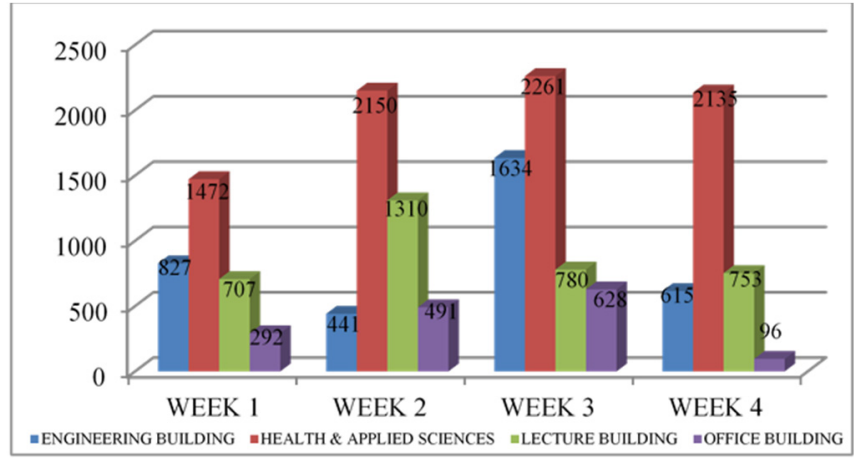

(a)

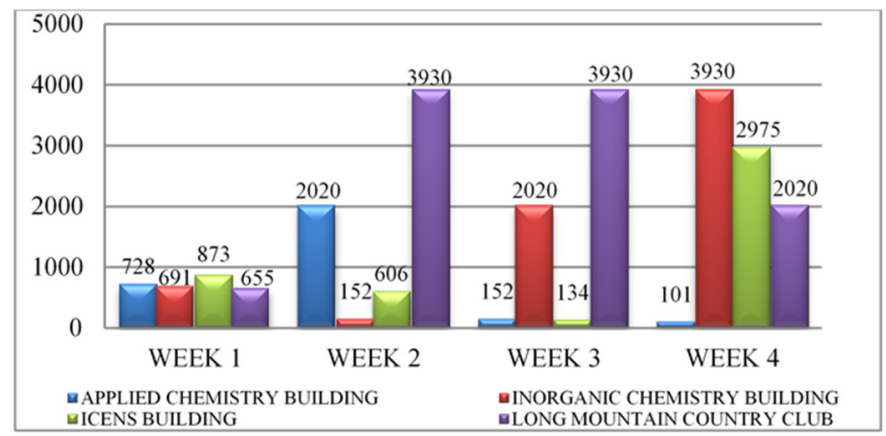

(b)

Figure 1: TSP concentrations for (a) Windhoek; and (b) Kingston. 
Table 2: Meteorological parameters during TSP measurements: Windhoek and Kingston.

\begin{tabular}{|c|c|c|c|c|c|c|c|c|}
\hline & \multicolumn{4}{|c|}{ CONCENTRATIONS (mg/m² day) } & RH (\%) & $\begin{array}{c}\text { TEMP } \\
\left({ }^{\circ} \mathrm{C}\right)\end{array}$ & $\begin{array}{l}\text { WIND } \\
\text { SPEED }\end{array}$ & $\begin{array}{l}\text { MIXING } \\
\text { HEIGHT }\end{array}$ \\
\hline \multicolumn{9}{|c|}{ Windhoek, Namibia } \\
\hline & ENG & H\&S & LECT & OFF & & & & \\
\hline WEEK 1 & 827 & 1472 & 707 & 292 & 18.4 & 17.7 & 3.33 & 170.45 \\
\hline WEEK 2 & 441 & 2150 & 1310 & 491 & 21.9 & 22.7 & 3.53 & 185.47 \\
\hline WEEK 3 & 1634 & 2261 & 780 & 628 & 24.3 & 23.4 & 3.03 & 147.32 \\
\hline WEEK 4 & 615 & 2135 & 753 & 96 & 28.2 & 24.6 & 1.05 & 30.13 \\
\hline Ave & 879.25 & 2004.5 & 887.5 & 376.75 & 23.2 & 22.1 & 2.735 & 133.34 \\
\hline SD & 527.342 & 359.4204 & 283.2743 & 232.51 & 4.12068 & 3.036445 & 1.141972 & 70.57486 \\
\hline \multicolumn{9}{|c|}{ Kingston, Jamaica } \\
\hline & APPLIED & INORG & ICENS & LMCC & & & & \\
\hline WEEK 1 & 728 & 691 & 873 & 655 & 72 & 23.835 & 1.958 & 82.839 \\
\hline WEEK 2 & 2020 & 152 & 606 & 3930 & 70 & 26.964 & 3.564 & 190.43 \\
\hline WEEK 3 & 152 & 2020 & 135 & 3930 & 68 & 26.138 & 3.187 & 159.89 \\
\hline WEEK 4 & 101 & 3930 & 2975 & 2020 & 70 & 25.929 & 2.093 & 90.036 \\
\hline Ave & 750.25 & 1698.25 & 1147.225 & 2633.75 & 71.5 & 25.717 & 2.701 & 130.80 \\
\hline SD & 89.970 & 1682.228 & 1256.181 & 1597.151 & 1.633 & 1.332 & 0.796 & 52.801 \\
\hline
\end{tabular}

The concentrations of TSP can be presented in order of decreasing abundance per sampling site and measurement week respectively as LMCC $>$ INORG $>$ ICENS $>$ APPLIED and W4 $>$ W2 $>$ W3 $>$ W1 for Kingston; and $\mathrm{H} \& \mathrm{~S}>\mathrm{LECT}>\mathrm{ENG}>\mathrm{OFF}$ and $\mathrm{W} 3>\mathrm{W} 2>\mathrm{W} 4>\mathrm{W} 1$ for Windhoek. The 30 day average $\left(600 \mathrm{mg} / \mathrm{m}^{2}\right.$ day $)$ residential and industrial $\left(1200 \mathrm{mg} / \mathrm{m}^{2}\right.$ day $)$ dust rates set by South African National Standards [13] were both exceeded by the Kingston site $\left(1557 \mathrm{mg} / \mathrm{m}^{2}\right.$ day), while the Windhoek $\left(1034 \mathrm{mg} / \mathrm{m}^{2}\right.$ day $)$ exceeded the residential average only.

In general, the Kingston concentrations were higher than Windhoek levels. This could be the results of precipitation, which was only experienced in Kingston, and not Windhoek, as Leung and Gustafson Jr. [3] confirmed that precipitation frequency can also have large impacts on air quality.

Similar calm conditions (wind speed of 2.73 and $2.7 \mathrm{~m} / \mathrm{s}$ ) were observed at the two study sites thus yielding average mixing height of $133.3 \mathrm{~m}$ for Windhoek and $130.8 \mathrm{~m}$ for Kingston. The mixing height values can still be debated considering the fact that, the calculations are based on equation 1 [14], which does not consider the location of the global positioning (latitude) of the two cities.

$$
\mathrm{h}=28(\mathrm{u})^{3 / 2}
$$

The high relative humidity for Kingston as compared to Windhoek was expected considering the contrasting (tropical and arid) environments. 


\subsection{Ozone and meteorological parameters}

Leung and Gustafson Jr. [3] observed that besides variations in emission rate, type, and sources and the mix of precursor species, $\mathrm{O} 3$ concentration is affected by solar radiation, air temperature, and mixing/transport. Figure 2 shows the concentrations measured in Windhoek, Namibia, and the associated meteorological parameters.

The concentrations measured for the 8 weeks ranged between 10 and $35 \mathrm{ppb}$ ( 0.01 to $0.035 \mathrm{ppm}$ ), which is considered "normal" considering the fact that concentrations of ozone near the earth surface normally range from 0.01 to 0.05 ppm (10-50 ppb), with background ranges from 0.002 to $0.006 \mathrm{ppm}$ [15].

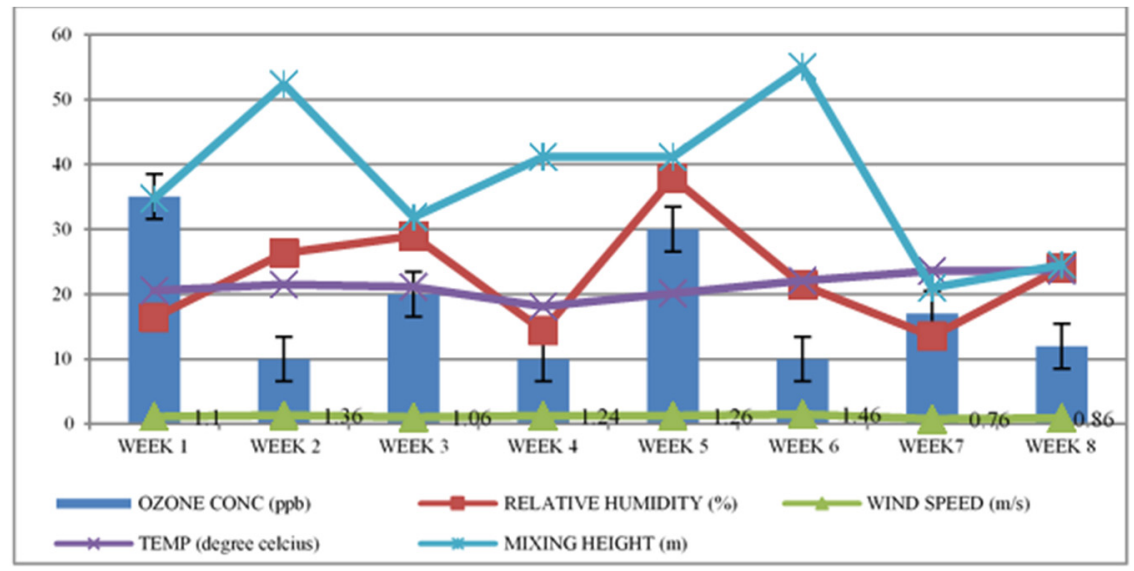

Figure 2: Ozone concentrations and meteorological parameters at the Windhoek study site.

In general, the temperature-ozone relation observed is in agreement with the report by IPCC [16] which reported a "weak" nonlinear relationship between temperature and tropospheric ozone for temperatures ranging from 22 to $26^{\circ} \mathrm{C}$ and a strong positive relationship above $30^{\circ} \mathrm{C}$.

The high mean solar radiation $\left(\mathrm{W} / \mathrm{m}^{2}\right)$ values were determined as 851,848 , $883,969,954,846,1015,1081$ from week 1 to 8 respectively (see Table 3 ); and the increase in ozone with increase in temperature for week 4 to 8 confirm conclusions by several researchers including Jacob et al. [17] who noted that while solar radiation moderates $\mathrm{O} 3$ production primarily by influencing NOx photolysis rate, air temperature affects ozone by changing biogenic emissions and conversion between NOx and peroxyacyl nitrate (PAN).

The mixing height values used in Figure 1 were calculated using equation 1 . An increase in mixing height with decrease in ozone concentrations for the entire study period ( 8 weeks) is in line with observations by [3], i.e. mixing/transport can dilute/advect ozone and pre-cursor concentrations and affect $\mathrm{O} 3$ formation and concentrations. The obvious increase in mixing height with increase in wind speed was observed because of the direct dependence of $h$ on wind speed. 
Table 3: Atmospheric conditions at the two sites.

\begin{tabular}{|c|c|c|c|c|c|}
\hline PERIOD & \multicolumn{3}{|c|}{ Mixing Height (m) } & $\begin{array}{c}\text { Ventilation } \\
\text { Rate }(\mathrm{m} . \mathrm{m} / \mathrm{s})\end{array}$ & $\begin{array}{c}\text { Solar Radiation } \\
\left(\mathbf{W} / \mathbf{m}^{2}\right)\end{array}$ \\
\hline \multicolumn{6}{|c|}{ Windhoek, Namibia $($ Roughness parameter $=1.0)$} \\
\hline & Eqn. 1 & Eqn. 2 & Eqn. 3 & Using Eqn. 3 & \\
\hline WEEK 1 & 34.75 & 137.5 & 1324.34 & 1456.78 & 851 \\
\hline WEEK 2 & 52.39 & 170 & 1617.25 & 2199.46 & 848 \\
\hline WEEK 3 & 31.84 & 132.5 & 1279.28 & 1356.03 & 883 \\
\hline WEEK 4 & 41.16 & 155 & 1482.06 & 1837.75 & 969 \\
\hline WEEK 5 & 41.11 & 157.5 & 1504.59 & 1895.79 & 954 \\
\hline WEEK 6 & 55.06 & 182.5 & 1729.91 & 2525.67 & 846 \\
\hline WEEK 7 & 20.99 & 95 & 91.303 & 715.39 & 1015 \\
\hline WEEK 8 & 24.48 & 107.5 & 1053.96 & 906.41 & 1081 \\
\hline Ave & 37.72 & 142.19 & 1260.34 & 1611.66 & 930.88 \\
\hline SD & 12.18 & 30.10 & 516.91 & 621.38 & 88.11 \\
\hline \multicolumn{6}{|c|}{ Kingston, Jamaica $($ Roughness parameter $=1.0)$} \\
\hline WEEK 1 & 82.84 & 244.75 & 1683.85 & 3296.98 & 359.74 \\
\hline WEEK 2 & 190.43 & 445.44 & 2994.73 & 10673.22 & 329.87 \\
\hline WEEK 3 & 159.89 & 398.40 & 2687.49 & 8565.03 & 420.58 \\
\hline WEEK 4 & 90.04 & 261.67 & 1794.35 & 3755.57 & 360.06 \\
\hline Ave & 130.8 & 337.57 & 2290.11 & 6572.7 & 367.56 \\
\hline SD & 52.80 & 99.52 & 650.06 & 3626.32 & 38.07 \\
\hline
\end{tabular}

\subsection{Environmental implications}

\subsubsection{Morphology of the TSP}

Particle pollution can also have important indirect effects on climate because of their ability to change the reflectivity of clouds and also indirectly influence cloud lifetime and precipitation [9]. Morphological analysis of the TSP filters from Namibian study sites was performed to determine the types of particulates/aerosols as shown in Figure 3. Morphological analysis have been used by researchers including Kgabi et al. [6] and Hamatui et al. [18] to estimate possible sources of particulates. This study uses the morphology to assess possible contribution to climate change and/or variability.

The shapes of atmospheric particles observed in this study can be classified into spherical, irregular, cubical, flake (geometrically irregular), fibrous, and flocks (chain-like). The flocks are often formed during incomplete combustion of fuels and contain a large amount of carbon [6]. Brown colorizations, with diamond 


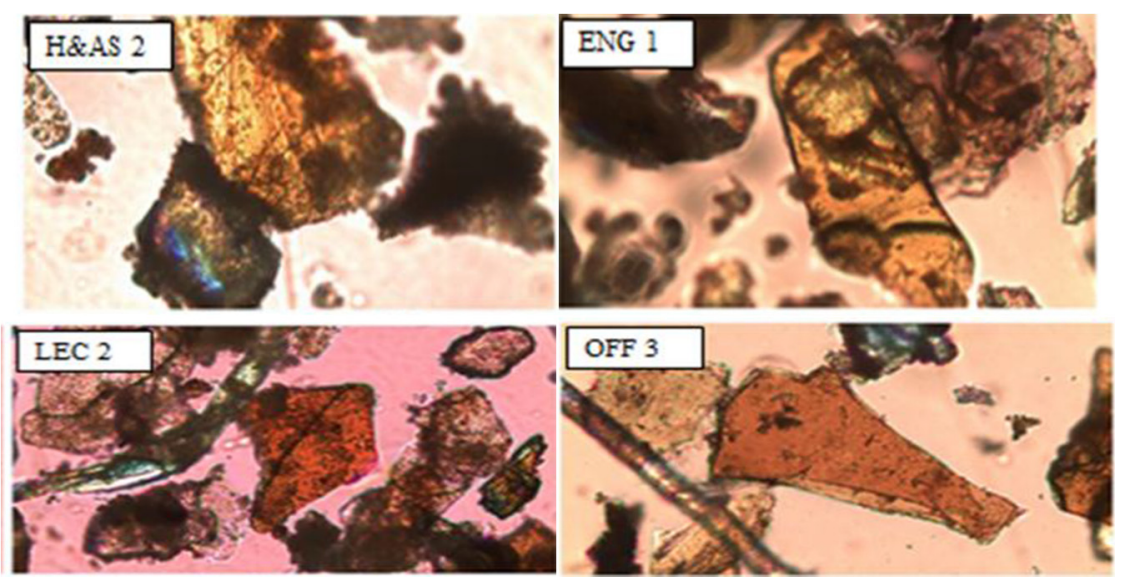

Figure 3: Morphology of TSP from Windhoek study sites.

shaped particles accompanied by central discoloration were observed, suggesting [18] intensive crushing activities as possible sources of particulate matter were also observed.

All aerosol species can play important roles in the radiative balance of the atmosphere (and hence climate change and variability) on urban, regional, and global scales [19]. Direct climatic effects come from particles' ability to absorb and scatter light. Different types of particles have different impacts on climate: some warm (e.g. black carbon); others cool (e.g. sulfates and nitrates) [9]. An understanding of the types of aerosols is important since they react differently when exposed to sunlight. For instance, sea salt particles reflect sunlight back out into space; and black carbon particles from burning of wood or fossil fuels absorb most of the sunlight that hits them [20].

In general, cloudy black particles indicating the presence of soot were observed on all four sites, with sand and cement particles. The particles observed in this study thus contribute more to warming and not cooling of the lower atmosphere.

\subsubsection{Ventilation and build-up of pollutants}

There are several atmospheric parameters contributing to build-up or dispersion of pollutants. These include mixing height or mixing depth (h), which signifies the height above the surface throughout which a pollutant can be dispersed; transport wind, the average wind speed and direction of all winds within the layer bounded by the surface and the mixing height; and ventilation rate (VR), which is the product of the mixing height and transport wind [21], and represents the ability of the boundary layer to get rid of the pollutants [22]. Table 3 shows the parameters used in this study to give an indication of how pollutants can disperse or build-up in the area thus affecting climate.

The intensity of solar radiation in Windhoek ranged from 846 to 1081 (mean $=$ 930.88) $\mathrm{W} / \mathrm{m}^{2}$ during the eight-week period while the Kingston sites measured 329.87 to 420 (mean $=367.56) \mathrm{W} / \mathrm{m}^{2}$ over the four-week study period. The contrast between the two sites confirms Power and Mills [23] observation that 
changes in the amount of insolation are likely due to changes in the amount of aerosols in the atmosphere. Typically, an increase in aerosols will decrease global and direct irradiance and increase diffuse irradiance [23]; and this could explain the high TSP levels and low solar radiation in Kingston.

A roughness parameter of $1.0 \mathrm{~m}$ indicated in Table 3 both for Kingston and Windhoek study sites was estimated following [24] since the two sites are not in the centre of the city, but have regular large obstacle coverage similar to suburbs. Roughness length, though not a physical length, can be considered a length-scale representation of the roughness of the surface. This is normally one tenth of the height of the terrain/surface roughness elements [24]. According to Linacre and Geerts [25], a lower roughness length implies less exchange between the surface and the atmosphere.

Dilution and dispersion (mixing/ transport) depends on wind, atmospheric stability, and mixing height/depth. The mixing height (h) was calculated using equations 1,2 [26] and 3 [27] shown below:

$$
\begin{gathered}
\mathrm{h}=125 \mathrm{u} \\
\mathrm{h}=0.089(\mathrm{u} / \mathrm{f})+85.1
\end{gathered}
$$

where $\mathrm{u}$ is the wind speed and $\mathrm{f}$ is the coriolis parameter, calculated for each study site using the equation:

$$
\mathrm{f}=2 \Omega \sin (\text { latitude) }
$$

Wang and Wang [7] considers mixing layer height (h) to be an important parameter that affects the near-surface air pollution concentration because it determines the volume in which the emitted pollutants are dispersed. The researcher also reported that $\mathrm{h}$ is related to the warming rate that is caused by the enhanced greenhouse gases.

The average mixing layer calculated using equation 3 (using latitude) was obtained in the range 91.30 to 1729.91 (average $=1260.34)$ m for Windhoek and 1683 to 2994.73 (2290.11) $\mathrm{m}$ for the Kingston site. The mixing height values were used to determine the ventilation rate (VR) of TSP and ozone concentrations. The VR for Windhoek was measured in the range of 715 to 2525 (average $=1611.66$ ) $\mathrm{m} . \mathrm{m} / \mathrm{s}$ and 3296.98 to $10673.22($ average $=6572) \mathrm{m} . \mathrm{m} / \mathrm{s}$. It is worth noting that high ventilation rate suggests that the pollutant will spread out quickly and through a deep layer of the atmosphere [28]; which suggests that the high pollution in Kingston will disperse at a faster rate. However, the VR is a measure of the horizontal transport of air within the mixed layer. Further studies to determine the stability, atmospheric boundary layer may help to determine both lateral and vertical dispersion parameters. Other parameters that need to be considered include the topography of each site.

\subsubsection{PM-Ozone interactions}

This study uses smog formation process to present an initial argument of the role of PM-ozone interactions in climate change and/or variability. The two pollutants variably affect climate. Akimoto [1] observed that aerosol lifetimes are approximately 1 to 2 weeks, which is significantly shorter than that of ozone, have 
a more uneven distribution than ozone, both horizontally and vertically, and are more concentrated near their source regions over continents and in the boundary layer.

The contributors to photochemical smog are primary pollutants (carbon monoxide and carbonaceous soots, nitrogen oxides, sulfur dioxide, and volatile hydrocarbons) and secondary pollutants formed in the troposphere during photochemical reactions that are driven by sunlight (ozone, Peroxyacyl nitrates (PANs), sulfate aerosols, nitrate aerosols, organic aerosols, etc.) [19].

Concentrations of both particulates and ozone can be enhanced by traffic and road-works through emission of carbonaceous soot containing oily organic coatings and associated polycyclic aromatic hydrocarbons (PAHs).

Gaffney et al. [19] purports that both aerosols and trace gas species present in smog are also important in determining the radiative balance of the troposphere, also known as the greenhouse effect because these can heat the atmosphere by absorbing infrared and solar radiation, trapping it in the troposphere.

The topography of Kingston and Windhoek include surrounding hills that can prevent horizontal winds from dispersing the pollutants. This adds to some "abnormal" arrangement of air masses (thermal inversions) where a warmer layer of air is trapped between layers of colder air, acts as a lid covering the city, thus increasing the pollutant concentrations, the rate of smog formation, and the contribution to climate.

\section{Conclusion}

The TSP concentrations were high in Kingston than in Windhoek. The ozone concentrations in Windhoek were relatively low (10 to $35 \mathrm{ppb})$. The atmosphericpollutant interactions were observed as in order of relative abundance as Kingston $>$ Windhoek for TSP, relative humidity, mixing height, and ventilation rate; and Windhoek $>$ Kingston for solar radiation.

The morphological analysis showed that, the net climate impact of emissions reduction strategies depend on reductions in particles of different types. Mitigation of the four short-lived climate pollutants (SLCPs), methane, tropospheric ozone, hydrofluorocarbons and black carbon, has been projected in $\mathrm{Hu}$ et al. [29] to reduce the warming trend by about $50 \%$ by 2050 . The morphology of particulates also showed the effect of daily activities of the domestic, traffic and industrial sectors to air quality and ultimately climate, and which need to change for realization of reduced pollution and climate effect.

The particulate-ozone interactions during ozone and smog formation can, depending on the source and type of aerosols, give an indication of the contribution to climate variability.

The authors suggest long term studies covering more cities and remote areas within the two countries (Jamaica and Namibia) and, including both historical data and projections; determination of atmospheric boundary layer and stability; and addressing the seasonality of the two pollutants. 


\section{Acknowledgements}

Support by The World Academy of Sciences (TWAS) - for the advancement of science in developing countries, Polytechnic of Namibia, and the International Centre for Environmental and Nuclear Sciences (ICENS) is highly acknowledged. The authors acknowledge Mr. Hall and the Department of Physics, University of the West Indies, Mona Campus for access to the raw meteorological data for the Jamaican sampling sites.

\section{References}

[1] Akimoto, H., Global Air Quality and Pollution, Science, 302, pp. 17161719, 5 December 2003, www.sciencemag.org

[2] Hassan, R., Scholes, R., Ash, N. (Eds), Ecosystems and Human Well-being: Current State and Trends, Volume 1, Chapter 13: Climate and Air Quality, Island Press, London, pp. 355-390, 2009.

[3] Leung, R.L., and Gustafson Jr., W.I., Potential regional climate change and implications to U.S. air quality, Letters, 32, L16711, 2005.

[4] Karl, T.R., Trenberth, K.E, Global Climate Change, Science, 302, 1719, 5 December 2003, www.sciencemag.org

[5] Mkoma, S.L., Physico-chemical characterisation of atmospheric aerosols in Tanzania, with emphasis on the carbonaceous aerosol components and on chemical mass closure, 2008.

[6] Kgabi, N., Shitaatala, E., Izaaks, C., Morphological Analysis of Fallout Dust in Windhoek, Namibia. Journal of Chemical, Biological and Physical Sciences, 2(4), 2201-2209, 2012.

[7] Wang, Y., Wang, K.C., Estimation of atmospheric mixing layer height from radiosonde data, Atmos. Meas. Tech., 7, 1701-1709, 2014.

[8] Commonwealth, http://thecommonwealth.org/our-work/small-states\# sthash.T1TjeUR5.dpuf, 2015.

[9] NASA, Aerosols: Tiny Particles, Big Impact, Earth Observatory, http://earthobservatory.nasa.gov/Features/Aerosols/, 2015.

[10] Kuhn, G., Standard Dust Monitoring Equipment Procedures. Kuhn Gerry Environmental and Hygiene, 2010. http://www.dust-monitoring equipment.com/falloutdust.htm, Accessed on: 26 May 2011.

[11] Biota Africa Weather. Windhoek (Satellite) (No.: 58557) - Daily values. http://www.biota-africa.org/weather/weatherstat_daily_we.php?loggerid crit=58557, 2014.

[12] Weather Underground, http://www.wunderground.com/history/, 2014.

[13] SANS, Ambient air quality - Limits for common pollutants. Pretoria: SABS Standards Division, SANS 1929, 2011.

[14] NIEUWSTADT, F.T.M, The turbulent structure of the nocturnal boundary layer, Journal of the atmospheric sciences, 41(14), 2202-2216, 15 July 1984

[15] University of North Carolina, Introduction to photochemical smog chemistry, The Atmosphere, www.unc.edu/.../smog-print.p 
[16] IPCC. The Regional Impacts of Climate Change: An Assessment of Vulnerability. United States of America: Cambridge University Press, 1998.

[17] Jacob, D. J., Logan, J.A., Gardner, G.M., Yevich, R.M., Spivakovsky, C.M., Wofsy, S.C., Sillman, S., Prather, M.J., Factors regulating ozone over the United States and its export to the global atmosphere, J. Geophys. Res., 98(D8), pp. 14,817-14,826, 1993.

[18] Hamatui, N., Kgabi, N., Naidoo, R., Izaaks, C. Characterisation of Fall-out Dust from a Charcoal Processing Plant, European Journal of Scientific Research, 127(1), pp. 39-45, 2014.

[19] Gaffney, J.S., Marley, N.A., Frederick, J.E, Formation and Effects of Smog Environmental and Ecological Chemistry - Vol. II.

[20] National Earth Science Teachers Association, Air Pollution and Climate Change - Windows to the Universe, http://www.windows2universe.org/ earth/climate/cli aerosols.html, Retrieved on 2 November 2014.

[21] Berry, D. Smoke Dispersion, Fire Weather Workshop, NWS Charleston County, 29 October 2009.

[22] Kdheks, n.d, http://www.kdheks.gov/bar/air-monitor/flinthillsinfo/KDHE Mixing-Height Transport Wind Category Day Info.pdf

[23] Power, H.C., Mills, D.M, Solar Radiation Climate Change Over Southern Africa And An Assessment Of The Radiative Impact Of Volcanic Eruptions, International Journal Of Climatology, 25, pp. 295-318, 2005.

[24] World Meteorological Organisation, WMO Guide to Meteorological Instruments and Methods of Observation, WMO-No. 8, I.5-12.

[25] Linacre, E., Geerts, B. 4/'99, Roughness length, http://www-das.uwyo.edu/ $\sim$ geerts/cwx/notes/chap14/roughness.html, Accessed on 12 February 2015.

[26] Bentley, C.W., Schulman, L.L., Estimating hourly mixing depths from historical meteorological data, Journal of Applied Meteorology, 18, pp. 772-780, 1979.

[27] Arya, S.P.S, Parameterizing the Height of the Stable Atmospheric Boundary Layer. Journal of Applied Meteorology, 20, pp. 1192-1202, 1981.

[28] AirFire, http://www.airfire.org/projects/wfdss-aq/help/glossary/, accessed on 12 February 2015.

[29] Hu, A., Xu, Y., Tebaldi, C., Washington, W.M., Ramanathan, V., Mitigation of short-lived climate pollutants slows sea-level rise, Nature Climate Change 3, pp. 730-734, 2013. 